\title{
Gastrointestinal helminths and their predisposing factors in different poultry management systems; Haromaya, Ethiopia
}

\author{
Solomon Mekuria ${ }^{1^{*}}$ and Mekonnen Bayessa ${ }^{1}$ \\ ${ }^{1}$ Hawassa University school of veterinary medicine \\ * Corresponding author school of veterinary medicine Hawassa University; P.O.Box 05 Hawassa \\ Ethiopia ; Email: solmk2010@gmail.com \\ https: / /dx.doi.org/10.4314/evj.v21i1.4
}

\begin{abstract}
Among several diseases, gastrointestinal parasites affect poultry production through retarded growth and reduced productivity. The severity varies according to management system and associated predisposing factors. Epidemiology of chicken gastrointestinal helminths were studied using coprological and necropsy examination, with the objectives to estimate the prevalence, identify species of helminths and associated predisposing factors in Haromaya town from November 2011 to April 2012. Fecal samples from selected chicken were collected from both intensive and extensive farms. Coprological examination on 384 chicken and 24 post mortem examinations were conducted. Out of 384 samples examined, $51.8 \%$ were positive of which a high prevalence of $110(28.6 \%)$ Ascaridia galli followed by $33(8.6 \%)$ of Heterakis gallinarum, 11(2.8\%) of Raillietina species and 44(11.5\%) mixed infection were recovered. Factors for the occurrence of GIT helminths were investigated using logistic regression models; where each assumed predisposing factor analyzed using uni-variable and followed by multi-variable logistic regression to determine the interaction and power of influence among factors. Accordingly, statistically significant difference $(\mathrm{p}<0.05)$ was observed when prevalence of helminths compared with breed, sex, age and management system separately using univariable logistic regression; whereas, when all predisposing factors subjected together using multi-variable backward stepwise analysis, it showed that the odds of local, Fayoumi and White Leghorn breeds had odds of $(\mathrm{OR}=6.4,50.8$ and 6.9) more likely to be affected than Bovan Brown breed with significant difference $(p<0.05)$. Male birds were 1.9 times more likely to be affected than female birds and birds in extensive management system were 2.8 times more likely to be affected than intensive farming system. The study indicated that
\end{abstract}


gastrointestinal (GIT) helminths were more prevalent in extensive management system than in intensive management system, the finding was associated with poor management system or due to poor bio-security. Therefore, there is a need to improve hygienic situation, especially in area where extensive management system prevails.

Keywords: Gastrointestinal; Haromaya; Helminths; Poultry; Production systems;

\section{Introduction}

Unlike developed countries where poultry production is under intensive management system, $95 \%$ of poultry production in Ethiopia is under free scavenge production system (Anon, 2004; Dawit Abebe et al., 2008). Currently due to policy shift towards privatization and mixed economy intensive poultry management is flourishing in certain institutions and private farms. A total of 56 million chickens are estimated to be present in the country (CSA, 2014/15). Urbanization and population growth has become a driving force for high poultry egg and meat demand in the country; whereas, modern production and management systems are at their infant stage in the country in general.

Beyond the source of food, poultry production is well known as an immediate cash source for rural community; where the community sale few numbers of chicken according to their cash need (Bremner and Johnston, 1996; Sainsbury, 1992). Rural poultry production is well integrated with other farming activities because they require little space, labor and initial investment compared to other farming activities; and plays a significant role in cultural and social life of rural people (Sonaiya, 1990).

Despite significant economic and nutritional contribution, quality management is still a major problem in this subsector. Consequently, an estimated $20 \%$ to $50 \%$ of mortality occurs due to various diseases (Alamargot, 1987; Alemu Yami, 1995). Among diseases, internal parasites are known to reduce productivity of poultry kept under different management systems. Infection of parasites exists after ingestion of helminths eggs or intermediate hosts like cockroaches, grass hoppers, ants and earthworms (Soulsby, 1986). Helminths infection results in reduction in food intake, injury to the intestinal wall and hemorrhage which causes poor absorption of nutrients and leads to weight loss (Soulsby, 1986). Particularly free scavenging chickens are infected with 
helminths because the environment can be easily contaminated by wild birds' droppings (Amin-Babjee et al., 1997; Magwisha et al., 2002).

Therefore, this study was designed to estimate gastrointestinal helminths prevalence and to determine predisposing factors in poultry farm managed under extensive and intensive management systems in Haromaya district.

\section{Materials and Methods}

\section{Description of the study area}

The study was conducted from November 2011 up to April 2012 within Haromaya district which is located in Eastern Ethiopia where Haromaya University exists. It is located $512 \mathrm{~km}$ away from Addis Ababa. The altitude is 2000 meters above sea level (m.a.s.l.) within $09^{\circ} 24^{\prime} 10^{\prime \prime} \mathrm{E}$ and $41^{\circ} 19^{\prime} 58^{\prime} \mathrm{N}$. The area have a relative humidity of $65 \%$ and annual rainfall of approximately $900 \mathrm{~mm}$; which includes bimodal distribution pattern, where short period rainfall is in March and April, whereas long rainfall is in July to September of the year (CSA, 2014/15).

Farmers practice mixed livestock and crop production. Among livestock production, free ranging poultry production is the most common practice; in addition, Haromaya University has intensive poultry farm in the study area.

\section{Study population}

Poultry of local and exotic breeds of both sexes and all age groups which were kept under different management systems in the study area were used. Study populations were all those chickens' from selected kebeles, intensive farm of Haromaya University and multiplication and distributing center of Haromaya Woreda Agriculture Office. Therefore, all free ranging poultry and two intensive production center were included for the sampling purpose. Among the exotic breeds found in the village White Leghorn was predominant. In most extensive farming system feeding style was scavenging whereas shelter was provided at night. Supplementary feed was given less frequently; major source of concentrate feed includes sorghum and maize, given in the morning and/or after noon and allowed to scavenge the whole day. Water was provided near shade area using container. 
In case of intensive farming system, chickens were kept indoor with medium to high bio-security. Feeding and watering of these birds were done via common trough for both deep-litter and cage systems.

\section{Study design and sample size determination}

Cross-sectional study design was conducted, where snap-shot fecal sample collection and postmortem examination were used. Sample size was determined using formula given by (Thrusfield, 2005) for simple random sampling technique. No previously published data was available in this area; therefore, $50 \%$ expected prevalence and $5 \%$ desired absolute precision was taken to calculate the required sample size using the formula $\mathrm{n}=1.96^{2} \times \mathrm{P}_{\exp }\left(1-\mathrm{P}_{\exp }\right) / \mathrm{d}^{2}$; Where $\mathrm{n}=$ sample size, $\mathrm{P}_{\mathrm{exp}}=$ expected prevalence, $\mathrm{d}=$ desired absolute precision, $1.96^{2}=\mathrm{Z}$ value at $95 \%$ confidence interval. Therefore, 384 fecal samples were collected and purposively 24 chickens were used for postmortem examination.

\section{Sample collection and coproscopic examination}

Fecal samples were collected using hand gloves directly from the vent or top surface of freshly voided feces and placed in airtight screw cup universal bottles. Samples were transported to parasitology laboratory of Haromaya University, College of Veterinary Medicine and stored at $4^{\circ} \mathrm{C}$ until examined. During sample collection information about predisposing factors like breeds, sex, age and all other management systems were recorded for each collected sample. Age groups were categorized as young $(<6$ months), middle age (between 6 months and one year) and older age (above 1 year up to 2.5 years) for the purpose of statistical analysis.

Samples were processed using floatation technique with saturated sodium chloride solution. Three grams of fecal sample were weighed and put into universal bottle and $42 \mathrm{ml}$ of floatation fluid was added then mixed thoroughly and allowed to settle in test tube, then presence or absence of egg was appreciated using cover slip on test tube method (Hendrix, 1998; Urquhart et al., 1996). Identification of helminths was done using a standard microscope under 10X objective magnification and helminthological standard manual used for identification of helminths eggs in poultry (Soulsby, 1986). 


\section{Data management and analysis}

Data generated during the study period was entered into Microsoft Excel spread sheets and summarized using descriptive statistics. Further risk factors were analyzed using uni and multiple logistic regressions by STATA soft ware program; risk factor was considered significant when p-value was less than 0.05 .

\section{Results}

\section{Prevalence and species of helminths identified}

In the present study, an overall prevalence of $51.8 \%$ of GIT helminths was observed (Table 1). Out of 384 fecal samples examined 110(28.6\%) Ascaridia galli, 33(8.6\%) Heterakis gallinarum, 11(2.8\%) Raillietina spp, 1(0.26\%) Syngamus trachea and 44(11.5\%) were mixed infection with two or more species of helminths mentioned above were observed as shown in Table 2.

Table 1. Prevalence of gastrointestinal parasites of poultry under extensive and intensive management system

\begin{tabular}{|c|c|c|c|c|c|}
\hline $\begin{array}{l}\text { Farming } \\
\text { system }\end{array}$ & No examined & Positive & $\begin{array}{c}\text { Prevalence } \\
(95 \% \mathrm{CI})\end{array}$ & $X^{2}$ & p-value \\
\hline Cage & 58 & 8 & $13.8[6.6,25.1]$ & & \\
\hline Deep-litter & 134 & 57 & $42.5[34.1,51.4]$ & 54.9 & 0.00 \\
\hline Backyard & 192 & 134 & $69.8[62.7,76.0]$ & & \\
\hline Total & 384 & 199 & $51.8[46.7,56.9]$ & & \\
\hline
\end{tabular}

The study result revealed that there was significant difference $(p<0.05)$ between intensive and extensive management system, (where intensive management were categorized as cage and deep-litter system, whereas extensive management were termed as backyard system). Therefore, the prevalence of $13.8 \%, 42.5 \%$ and $69.8 \%$ was observed in cage, deep-litter and backyard management systems, respectively. Parasite infection under different management systems indicates that cage system had only Ascaridia galli species of helminths, whereas both deep-litter and backyard harbored different parasite species as shown in Table $1 \& 2$. 
Table 2. Different GIT helminths parasites recovered in the fecal examination under different management system

\begin{tabular}{lccccccc}
\hline \multicolumn{7}{c}{ Species of helminths observed } & \\
\hline $\begin{array}{l}\text { Housing } \\
\text { system }\end{array}$ & no. & $\begin{array}{c}\text { Positive } \\
(\%)\end{array}$ & Syngamus & A. galli & $\begin{array}{c}\text { H.gallin } \\
\text { arum }\end{array}$ & $\begin{array}{c}\text { Raillie } \\
\text { tina } \\
\text { spp }\end{array}$ & $\begin{array}{c}\text { mixed } \\
\text { infection* }\end{array}$ \\
\hline Cage & 58 & $8(13.8 \%)$ & - & 8 & - & - & - \\
Deep-litter & 134 & $57(42.5 \%)$ & - & 29 & 11 & 6 & 11 \\
Backyard & 192 & $134(69.8 \%)$ & 1 & 73 & 22 & 5 & 33 \\
Total & 384 & $199(51.8 \%)$ & (1) $0.25 \%$ & $110(28.6 \%)$ & $33(8.6 \%)$ & $11(2.9 \%)$ & $44(11.5 \%)$ \\
\hline
\end{tabular}

*= indicates infection of two or more helminths co-existence

\section{Prevalence of helminths as compared with biotic risk factors}

Prevalence was analyzed using uni and multi variable logistic regression against breeds, sex, and age. It has indicated that all breeds were more or less infected by different helminths species and there was no refractory breed in the study. However there was prevalence difference among breeds.High prevalence was recorded in local breeds followed by White Leghorn, then followed by Fayoumi and Bovan Brown with prevalence of 40(95.2\%), 133(57.4\%), $16(37.1 \%)$ and $10(13.5 \%)$, respectively. High prevalence was observed in males $79(71.8 \%)$ than in females $120(43.79 \%)$. Among age groups older chickens' had higher prevalence $90(66.17 \%)$, followed by middle age group with prevalence of $84(49.4 \%)$ and low prevalence $25(32.5 \%)$ was observed in young age group. The finding was significantly different $(\mathrm{p}<0.05)$ among different breeds, sexes, age groups and management systems (Table 3 ).

Table 3. Logistic regression analysis of prevalence of GIT helminths compared with biotic factors

\begin{tabular}{lccccc}
\hline Factor & Examined & Positive & $\begin{array}{c}\text { Prevalence } \\
(\mathbf{9 5 \% C I )}\end{array}$ & OR 95\%CI & p-value \\
\hline Breed & & & & & \\
$\quad$ Bovan Brown & 74 & 10 & $13.5[7.0,23.9]$ & 1 & \\
White Leghorn & 233 & 133 & $57.1[50.4,63.4]$ & $8.5[4.2,17.4]$ & 0.00 \\
Fayoumi & 35 & 16 & $45.7[29.2,63.1]$ & $5.3[2.1,13.8]$ & 0.00 \\
$\quad$ Local & 42 & 40 & $95.2[82.1,99.1]$ & $128[26.7,614.5]$ & 0.00 \\
Sex & & & & & \\
\hline
\end{tabular}




\begin{tabular}{|c|c|c|c|c|c|}
\hline Factor & Examined & Positive & $\begin{array}{l}\text { Prevalence } \\
\quad(95 \% \mathrm{CI})\end{array}$ & OR $95 \% \mathrm{CI}$ & p-value \\
\hline Female & 274 & 120 & $43.8[37.8,49.8]$ & 1 & \\
\hline Male & 110 & 79 & $71.8[63.3,79.7]$ & $3.2[2.02,5.28]$ & 0.00 \\
\hline \multicolumn{6}{|l|}{ Age group } \\
\hline$<6$ months & 78 & 25 & $32.1[22.1,43.7]$ & 1 & \\
\hline $6 \leq 1$ year & 170 & 84 & $49.4[41.7,57.9]$ & $2.0[1.17,3.63]$ & 0.01 \\
\hline $1<2 \frac{1}{2}$ year & 136 & 90 & $66.2[57.4,73.9]$ & $4.1[2.29,7.50]$ & 0.00 \\
\hline
\end{tabular}

Prevalence of gastrointestinal parasite when compared with abiotic factors: The prevalence of gastrointestinal parasite was compared against abiotic factors like watering, feeding, bedding and frequency of litter cleaning using univariable logistic regression as shown in Table 4.

Table 4. Comparison of prevalence of GIT helminths with abiotic factors using univariable logistic regression analysis

\begin{tabular}{|c|c|c|c|c|c|}
\hline $\begin{array}{l}\text { Management } \\
\text { system }\end{array}$ & $\begin{array}{c}\text { No. } \\
\text { examined }\end{array}$ & Positive & $\begin{array}{c}\text { Prevalence } \\
(95 \% \text { CI })\end{array}$ & OR(95\% CI) & P. value \\
\hline \multicolumn{6}{|l|}{ Farming system } \\
\hline Intensive & 192 & 65 & $33.9[27.3,41.0]$ & 1 & \\
\hline Extensive & 192 & 134 & $69.8[62.7,76.0]$ & $4.5[2.9,6.9]$ & 0.00 \\
\hline \multicolumn{6}{|c|}{ Watering system } \\
\hline Water trough & 134 & 57 & $42.5[34.1,51.3]$ & 1 & \\
\hline Water pipe & 58 & 8 & $13.8[6.5,25.6]$ & $4.7[2.0,11.1]$ & 0.00 \\
\hline Scavenge & 192 & 134 & $69.8[62.7,69.0]$ & $3.1[1.96,4.9]$ & 0.00 \\
\hline \multicolumn{6}{|l|}{ Feeding system } \\
\hline Feed trough & 134 & 57 & $42.5[34.1,51.3]$ & 1 & \\
\hline Cage system & 58 & 8 & $13.8[6.5,25.6]$ & $4.7[2.0,11.1]$ & 0.00 \\
\hline Scavenging & 192 & 134 & $69.8[62.7,76.0]$ & $3.1[1.9,4.9]$ & 0.00 \\
\hline \multicolumn{6}{|l|}{$\begin{array}{l}\text { Frequency of } \\
\text { cleaning }\end{array}$} \\
\hline 3-6 month & 134 & 57 & $42.5[34.1,51.4]$ & 1 & \\
\hline Daily & 58 & 8 & $13.8[6.5,25.9]$ & $0.2[0.09,0.49]$ & 0.00 \\
\hline Irregularly & 192 & 134 & $69.8[62.7,76.0]$ & $3.2[1.96,4.94]$ & 0.00 \\
\hline \multicolumn{6}{|c|}{ Fecal consistency } \\
\hline Semi solid & 257 & 124 & $48.2[42.0,54.5]$ & 1 & \\
\hline Soft & 120 & 71 & $59.2[49.8,67.9]$ & $1.5[1.0,2.4]$ & 0.04 \\
\hline Diaharric & 7 & 4 & $57.1[20.2,88.1]$ & $1.4[0.3 .6 .5]$ & 0.64 \\
\hline
\end{tabular}

Ethiop. Vet. J., 2017, 21 (1), 40-53 
It was observed that all considered risk factors showed significant difference $(\mathrm{p}<0.05)$. Multi variable backward stepwise analysis using logistic regression showed that few risk factors were significantly different $(p<0.05)$, whereas others were dropped out due to co-linearity. Feeding, watering, frequency of cleaning, bedding and age group were dropped. Therefore, predisposing factors like local breeds, Fayoumi, White Leghorn, male, and extensive management showed statistically significant $(\mathrm{p}<0.05)$ differences. The odds of local, Fayoumi and White Leghorn breeds ( $\mathrm{OR}=6.4,50.8$ and 6.9) were more likely to be affected than Bovan Brown breed. Male birds were affected with odds of 1.9 times more likely than female birds, whereas birds in extensive management system were affected with odds of 2.8 times more likely than intensive farming system as shown in Table 5 .

Table 5. Multivariable logistic regression analysis of biotic and abiotic risk factors as compared with prevalence of GIT helminths

\begin{tabular}{lccccc}
\hline Risk factor & $\mathbf{n}$ & Positive & $\mathbf{\% , 9 5 \% [ C I ]}$ & Adjusted OR,95\%[CI] & p-value \\
\hline Breed & & & & & \\
White Leghorn & 233 & 133 & $57.1[50.4,63.4]$ & $6.9[2.6,18.7]$ & 0.00 \\
Fayoumi & 35 & 16 & $45.7[29.2,63.1]$ & $50.8[10.1,254.2]$ & 0.00 \\
Local & 42 & 40 & $95.2[82.1,99.1]$ & $6.4[3.1,13.4]$ & 0.00 \\
Sex & & & & & \\
Male & 110 & 79 & $71.8[63.3,79.7]$ & $1.9[1.12,3.26]$ & 0.01 \\
Extensive & 192 & 134 & $69.8[62.7,76.0]$ & $2.8[1.7,4.7]$ & 0.00 \\
farming & & & & & \\
\hline
\end{tabular}

\section{Post-mortem findings}

Twenty four chickens (nine from backyard and 15 from deep-litter management systems) were examined for helminths infection, thirteen were positive for different types of helminths; which showed $54 \%$ of prevalence based on adult worm recovery and it was almost similar to that of coproscopic finding (51.8\%). The findings of postmortem examination revealed a prevalence of $29.2 \%$ A. galli, $12.5 \% \mathrm{H}$. gallinarum, $4.2 \%$ Raillietina spp. and $8.3 \%$ mixed infection. The prevalence of species of parasite recovered from necropsy was in consistent with the findings of coproscopic examination. 


\section{Discussion}

In this study the overall prevalence of GIT helminths was $51.8 \%$ and $54 \%$ based on coprological and post mortem examination, respectively. The finding of the present study is higher than $33.5 \%$ reported by (Irungu et al., 2004) in South Eastern Kenya. The difference in prevalence might be due to management and agro-climatic variation in the two study areas.

In this study Ascaridia galli with prevalence of $28.6 \%$ and Heterakis gallinarum $8.6 \%$ followed by mix of nematode and Raillietina spp $11.5 \%$, and Raillientina spp alone $2.8 \%$ were identified. The same trend in prevalence was observed in necropsy finding. Even though coproscopic examination is less sensitive to diagnose than adult worms count, high prevalence of parasite was observed, which indicates that GIT parasites were a problem in the study area and there was no experience of providing prophylactic measure to control helminths. Similar findings of $A$. galli and $H$. gallinarum followed by cestode spp were recorded by (Permin et al., 1997; Birhanu Mekibib et al., 2014), but high cestode spp followed by nematodes recovered by Irungu et al., (2004). Only A. galli spp and different cestode spp have been identified in semi-intensive management system at Debre Zeit agricultural research center by (Yacob Hailu and Hagos Ashenafi, 2013). This variation in prevalence by different researchers might be due to management and ecological variation in respective study areas.

There was a significant difference in the prevalence of GIT nematode (Ascaridia galli and Heterakis gallinarum) and cestode (Raillietina spp) in deep-litter and backyard than cage system. In cage system only A. galli with low prevalence of $13.8 \%$ was observed. Similar findings were observed by (Permin et al., 1995), where free ranging and deep-litter chicken had high prevalence of nematodes and cestode spp. than in cage system. Birhanu Mekibeb et al., (2014) have reported high prevalence of nematode species from scavenging chickens in outskirts of Hawassa town. Current and previous studies confirmed that there is high prevalence in backyard and deep-litter management system than cage system, which indicated the role of hygienic management that play significant impact to increase productivity of poultry. Different predisposing factors like breed, sex, extensive management system had statistically significant $(\mathrm{p}<0.05)$ differences in the prevalence of GIT nematode and cestode parasites. However, breed and sex might be confounding factors of management system, as these 
biotic factors have no biological plausible effect on infection, but it requires further study to verify the findings in this study.

Among the breeds of chicken examined lower prevalence was observed in Bovan Brown, this could be also a confounding factor since most of these Bovan Brown breed samples were collected from cage system and most of the other breeds were sampled from deep-litter and backyard systems. Therefore, difficult to conclude Bovan Brown breed of chickens appear to be resistant to GIT parasites. In cage farming system which has relatively good hygiene, regular cleaning, chickens are less exposed to infective larval stage and that might be the main factor for low prevalence in this breed, but it is still important to verify the finding through further research.

There was significant difference between male and female chickens in the prevalence of GIT helminths. This may be due to management factor because most of the female chickens were sampled from cage system. Almost all males were sampled from backyard production system which can lead to expose more to contaminated feed, intermediate host than caged ones. Therefore, sex couldn't be a contributing factor rather it is confounder. Among the age groups the adult chicken had higher prevalence than middle and young age groups. This could be due to the adult chickens that might be exposed repeatedly for infective larval stage, coupled with backyard management system that might have contributed for higher prevalence in older age group than younger groups.

The management system like watering, feeding, bedding and frequent cleaning of the litter are confounding factors; where feeding, watering and cleaning varies according to the management systems. Cage system has better hygienic activity in feeding, watering and cleaning than backyard. Bedding system also directly coincides with management system, where deep-litter and backyard management being relatively unhygienic than cage system. Logistic regression shows that the odds of deep-litter and backyard systems were $(\mathrm{OR}=4.6$; $\mathrm{CI}=$ $[2.0,10.5])$ and $(\mathrm{OR}=3.1 ; \mathrm{CI}=[1.9,4.9])$, respectively; more likely to be exposed for high prevalence of helminths than cage system.

Previous studies indicate that there was high prevalence of Ascaridia galli $69 \%$ in Iran, $90.7 \%$ in Kenya and $88.7 \%$ in Bangladesh as reported by (Ananda et al., 2008, Eslami et al., 2009; Kaingu et al., 2010) respectively. However, in this study there was lower prevalence (28.6\%); this may be due to sampling technique where the current study was conducted using fecal samples, 
whereas most other studies were conducted using adult worms' count, through post mortem examination, which is more sensitive and gold standard than egg count.

Ascaridia galli has a major effect on the health of chicken sharing feed from one source, thus cause stunted growth and low productivity as the result of intestinal mucosa damage (Gordon and Jordan, 1982; Soulsby, 1986; Permin et al., 1995). Heterakis gallinarum was recorded as the second most prevalent nematode species in this study. It was lower when compared with that of (Irungu et al., 2004) in Kenya (21.3\%), (Hagos Ashenafi and Eshetu Yimer, $2002)$ in the central Ethiopia (24\%). This may be due to differences in management (Indoor, outdoor, feeding, bedding etc) and favorable condition for the survival and transmission of infective larval stages as well as availability of intermediate hosts.

Heterakis gallinarum itself has very little to no pathogenic effect in chicken but plays a major role in the epidemiology of Histomoniasis. Eggs of Heterakis gallinarum contain Histomonas meleagridis and ingested by young, will cause histomoniasis (black head) (Gorden and Jordan, 1982; Soulsby, 1986; Urquhart et al., 1996). The third prevalent GIT helminth parasite in the study area was cestode mixed with helminths. It was lower than the report by (Hagos Ashennafi and Eshetu Yimer, 2002) in central Ethiopia 86.32\%, (Kaingu et al.,2010) in Kenya $13.24 \%$ and (Haider et al.,1999) in Pakistan $16.0 \%$. The major difference could be due to sampling technique, where coproscopic examination was used in this study. Though, the number was small, post mortem examination has also revealed consistent result in prevalence. Therefore, ecology and season of the study period might have affected the occurrence of the parasite in different study areas.

\section{Conclusion and recommendations}

Despite the significant role of poultry production as a source of animal protein and immediate cash income generation, both intensive and extensive poultry production systems in the study were highly exposed with high parasitic burden; which of course leads to low area productivity. Especially in deep-litter and free scavenging management systems there were high parasites prevalence. In addition significant prevalence difference was observed in certain assumed predisposing factors.. Therefore, the present study clearly indicates 
that chicken kept under intensive production system had a better bio-security than extensive farming system. On the other hand, those kept under extensive production system might have been highly exposed to infective stage larvae or intermediate host due to their free scavenging nature. Further study involving the role of predisposing factors should be conducted. In addition, proper sanitation and good husbandry practices should be employed to interrupt the life cycle of gastrointestinal parasites of poultry. Furthermore, traditional poultry production system has to be improved into small scale intensive farming system inorder to leverage the existing poor production output.

\section{References}

Abebe, D., Tamirat, D. and Setotaw, R. 2008. Draft report on over view and ground paper on Ethiopian Poultry Sector. In: Relevance of HPAI research in Ethiopia, Addis Ababa, June 30, 2008

Almaragot, J. 1987: Avian Pathology of Industrial Poultry Farms in Ethiopia. In: proceeding of first National Livestock Improvement Conference (NLIC), Institute of Agricultural Research February 11-13, 1987. Addis Ababa, Ethiopia, pp: 114-119

Ananda, K. L., Puttalskshmamma,G. C., Prothuish, P. R., Mamath,G. S., and Suguna, R., 2008. Pevalence of gastro-intestinal parasites of poultry in and around Banglor. Vet. World. J., 1(7), 201-202.

Anon, T. 2004. State of Ethiopia Animal Genetic Resource Country Report. A contribution is to the first report on the state of world's animal genetic resource. Institute of bio-diversity conversation (IBC), Addis Ababa, Ethiopia

Ashenafi, H. and Yimer, E. 2002. Study on Gastrointestinal helminths of local chicken in central Ethiopia. Ethiop. Vet. J., 6 (2), 42-53

Mekibeb, B. Haileyesus, D. and Shiferaw, D. 2014. Gastrointestinal Helminths of Scavenging Chickens in Outskirts of Hawassa, Southern Ethiopia. Global Vet., 12 (4), 557-561.

Bremner, J. and Johnson, M. 1996. The Poultry Meat Industry, Poultry Meat Hygiene and Inspection. W.B. Sounders companies Ltd, London.

CSA, 2014/15. Agricultural Sampling Survey; Central Statistical Authority (CSA), Vol. II Addis Ababa, Ethiopia.

Eslami, A., Ghaemi, P. and Rahbari, S. 2009. Parasitic infection of Free-Range chickens from Golestan province, Iranian J. Parasitol.,4(3), 10-14.

Gordon, R. F. and Jordan, F. T. 1982. Poultry Diseases, $2^{\text {nd }}$ Ed. Bailliere Tindall, London, UK. Pp. 191-197. 
Haider, A. S., Anwar, U. A., Muhammad, N. K., Iqbal. L. and Qudoos, A.1999. Comparative study on prevalence of cestode parasites in indigenous and exotic chicken at Faisalabad. Department of Veterinary Parasitology, University of Agriculture, Faisalabd, Pakistan. Int. J. Agric. Biol., 4, 277-279.

Hailu,Y. T. and Ashenafi, H. T. 2013. Occurrence of ectoparasites and gastro-intestinal helminths infections in Fayoumi chickens (Gallus gallus Fayoumi) in Debre Zeit Agricultural Research Center Poultry Farm, Oromia Region, Ethiopia. JVMAH 5(4), 107-112.

Hendrix, C. M., 1998. Diagnostic Veterinary Parasitology, $2^{\text {nd }}$ ed. An affiliate of Elsevier Science, Publisher, B.V. Pp 45-57.

Irungu, L.W., Kimani, R. N. and Kisia, S. M. 2004. Helminths parasites in the intestinal tract of indigenous poultry, in part of Kenya. J. South. Afr.Vet. Assoc., 75(1), 58-59.

Kaingu, F. B., Kibor, A. C., Shivaro, R., Kutima, H., Okeno, T., Waihenya, R. and Kahi, A. K. 2010. Prevalence of gastro-intestinal helminths and coccidian in indigenous chicken from different agro-climatic zones in Kenya. Animal Science Egerton University, Nairobi, Kenya. Afr. Int. Agri. Res., 5(6), 458-462.

Magwisha, H. B., Kassuka, A. A., Kyugaard,N.C., Permin,A., 2002. A comparison of the prevalence and burden of helminths infections in growers and adult free-range chickens Trop. Anim. Hlth. Prod., 34, 205-214.

Permin, A., Magwisha, Kassuku, A. A., Nansen, P., Bisgaard, M., F. and Gibbons, L. 1997. A cross-sectional study of helminths in rural scavenging poultry in relation to season and climate. J. Helminthol., 71, 233-240.

Permin, A., Nansen., P., Bisgaard, M., Pearman, M. 1995. Ascaridia gali population in chicken follows single infection with a different dose levels. Parasitol. Res., 83, 614-617.

Sainsbury, D., 1992. Poultry health and management: Chicken, Duck, Turkey, Geese,

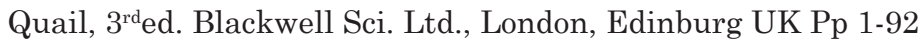

Sonaiya, E. B. 1990. The context and prospective for development of small holder rural poultry production in Africa. In: Proceeding CTA Seminar on the small holder rural poultry production 9-13 October 1990, Thesalonici, Greece, 1, 35-55.

Soulsby, E. J. L. 1986. Helminths Arthropods and Protozoa of Domesticated Animals, $7^{\text {th }}$ ed. Bailliere Tindall,London.

Thrusfiled, M. 2005. Veterinary Epidemiology, $3^{\text {rd }}$ ed. Blackwell Sci. Ltd, London, Edinburg UK, Pp 312-321. 
Urquhart, G. M., Armour, J., Duncan, J. L., Dunn, A. M., Jennings, F.W. 1996. Veterinary Parasitology. Churchill Livingstone Inc., New York. Pp. 8-170.

Yami, A. 1995. Poultry production in Ethiopia; World .Poult. Sci. J., 52, 197-201. 